\title{
Acute and Subchronic Oral Toxicities of Justicia pectoralis $J$. Extract in Wistar Rats
}

\author{
Alicia Lagarto*, Viviana Bueno, Isbel Guerra, Odalys Valdés, Tatiana Gabilondo and \\ Jorge Rodríguez
}

Biologic Control Laboratory, Drug Research and Development Centre (CIDEM), Cuba

\begin{abstract}
We have studied the acute and subchronic oral toxicities of Justicia pectoralis $\mathbf{J}$ hydroalcoholic extract in Wistar rats. In acute test, both sexes of adult Wistar rats were given single po dose of J. pectoralis extract at $2000 \mathrm{mg} / \mathrm{kg}$. Following euthanasia 14 days later, mortality and signs of toxicity were not observed. In subchronic test, J. pectoralis extract was po administered to both sexes of Wistar rats at 10,100 and $1000 \mathrm{mg} / \mathrm{kg} /$ day, 5 days per week for 90 days. The major toxicological endpoints examined included animal body weight, food intake, selected tissue weights, and histopathological examinations. In addition, we examined blood elements and blood chemistry. Of the blood elements, the blood clotting time was significantly affected in males and females after 90 days. For blood chemistry parameters, cholesterol, ALT, bilirubin, and urea were affected. Organs and tissues abnormalities were not observed in histopathological examination. These results indicate that the effects observed are low and include slight variations in blood clotting time and biochemical parameters.
\end{abstract}

Keywords: Justicia pectoralis J., Acantaceae, acute, subchronic, toxicity, Wistar rats.

\section{INTRODUCTION}

Justicia pectoralis Jacq is a plant species native of the American tropics (Acantaceae family). This plant has been widely used as antibacterial, anti-inflammatory and sedative agent [1]. Hydroalcoholic extract from J. pectoralis presented a significant anti-inflammatory effect intraperitoneally with the formalin test in mice and carrageenan induced edema. On the other hand, the hydroalcoholic extract showed bronchodilator activity in isolated guinea-pig trachea [2]. Coumarin has been identified as responsible metabolite for antibacterial, anti-inflammatory and antinociceptive effects of J. pectoralis [1].

In our country, most scientific evidence regarding its effectiveness as a sedative agent is based on animal and laboratory studies. Effects on central nervous system are similar to these described for tranquilizers drugs. However, pharmacological action of this plant does not correspond with the pharmacological profile of antipsychotic and tricycles antidepressant drugs [3-4].

Available data of toxicological studies are insufficient to support the safety of $J$. pectoralis extract. Nevertheless, the reported results demonstrate the absence of toxicity of extracts obtained from $J$. pectoralis. A study with lyophilized aqueous extract $\mathrm{LD}_{50}$ value for intravenous route in mice was $1344 \mathrm{mg} / \mathrm{kg}$ classifying the extract as non toxic. In rats, the maximum dose theoretically administrable for intraperitoneal route was $4000 \mathrm{mg} / \mathrm{kg}$ without toxic signs [5]. Genotoxic studies with hydroalcoholic extract, using micro-

*Address correspondence to this author at the Biologic Control Laboratory, Drug Research and Development Centre (CIDEM), 17 No. 6208 e/ 62 y 64, Playa, Havana City, Cuba; Tel: (537) 209 5451; Fax: (537) 833 5556; E-mails: alicialp@infomed.sld.cu; cidem.cb@infomed.sld.cu nucleus test in mice bone marrow, did not show genotoxic effect at 500,1000, and $2000 \mathrm{mg} / \mathrm{kg}$ doses [6].

The overall objective of this investigation was to characterize the acute and subchronic toxicity of $J$. pectoralis hydroalcoholic extract by oral route in both sexes of adult, Wistar rats. An additional aim was to identify lowestobserved-adverse-effect levels (LOAELs) and no-observedadverse-effect levels (NOAELs) for acute and subchronic $J$. pectoralis extract exposure.

\section{MATERIALS AND METHODOLOGY}

\section{Plant Extract Preparation}

The plant foliage was collected in summer (August month) and voucher specimens were kept in Herbal "Dr. Juan Tomás Roig" of EEPM ( $\mathrm{N}^{\circ}$ 4648). Plant material was dried in recycled air stove to $45^{\circ}$ and chopped in a windmill with mesh size of the particles up to $5 \mathrm{~mm}$. Dried J. pectoralis foliage was extracted with ethanol $30 \%$ for nine days (repercolation with four extractions). The extract obtained was dried using a spray drier equipment. The drying was carried out with $1400^{\circ} \mathrm{C}$ of entrance temperature and $75.4{ }^{\circ} \mathrm{C}$ of exit temperature, being the bomb flow between 4 and 5 . The dry powder obtained was used for the studies.

\section{Plant Extract Analysis}

The extract was standardized in accordance with the organoleptics properties, the water content, and simple coumarin content. Water content was determined by Karl Fisher method [7]. Coumarin content was assessed by highperformance liquid chromatography [8]. HPLC was performed on Aluspher ${ }^{\circledR} 100$ (RP-select B $5 \mathrm{~mm}$ ) pre-column and Lichrospher ${ }^{\circledR} 100$, RP 18 column $(250 \mathrm{x}$ $4 \mathrm{~mm}, 5 \mu \mathrm{m})$ with a mixture of methanol/water $(60: 40)$ as mobile phase. The chromatography conditions were mobile 
phase flow $1 \mathrm{ml} / \mathrm{min}$, UV detector of $\lambda=274 \mathrm{~nm}$, and injection volume $20 \mu \mathrm{l}$. Twenty five $\mathrm{mg}$ of $J$. pectoralis extract in $25 \mathrm{ml}$ of mobile phase was used for determining coumarin content. The quantification was performed by calibration curve of reference standard of simple coumarin (Aldrich Chemical Co.) in a concentration range of 4.0-20.0 $\mathrm{mg} / \mathrm{ml}$.

The organoleptics properties found in the raw material were of a homogeneous powder of brown color with characteristic scent. The humidity content was $1.4 \%$. The simple coumarin content was $9.46 \mathrm{mg}$ for each gram of dry powder.

\section{Animals}

Animal care was in conformity with Canadian Council for Animal Care guidelines. All animals used in this study were outbred Wistar rats, purchased from Biologic Control Lab. CIDEM (Havana, Cuba). Both sexes of rats were used in the study. Rats weighing $150-200 \mathrm{~g}$ were used in acute toxicity assay. Rats used in subchronic toxicity assay were 6 weeks old at the onset of dosing. Rats were housed by sex in polycarbonate cages with ad libitum access to standard diet CMO 1000 (Centro Nacional para la Producción de Animales de Laboratorio, Havana, Cuba) and tap water. Animals were maintained under a light: dark schedule of $12 \mathrm{~h}: 12 \mathrm{~h}$ at a temperature of $20^{\circ} \mathrm{C}$.

\section{Acute Toxicity Test}

Three male and three female rats were randomly assigned to two groups treated with $2000 \mathrm{mg} / \mathrm{kg}$ of J. pectoralis extract. Animals were fasted for $16 \mathrm{~h}$ prior to dosing. Rats were dosed by po gavage, using a stainless steel feeding needle, with $20 \mathrm{ml} / \mathrm{kg}$ body weight of aqueous solution containing $10 \%(\mathrm{w} / \mathrm{v})$ of $J$. pectoralis powder. The dose delivered was therefore, $2000 \mathrm{mg} / \mathrm{kg}$ of $J$. pectoralis powder. All rats were monitored continuously for $24 \mathrm{~h}$ after dosing for signs of toxicity. For the remainder of the 14-day study period, animals were monitored daily for any additional behavioral or clinical signs of toxicity and weekly for changes in body weight. Rats were euthanized on day 14 by lethal dose of sodium pentobarbital, and organs and tissues were examined macroscopically for toxicant-induced changes [9].

\section{Subchronic Toxicity Test}

Fourteen animals of each sex were exposed to $J$. pectoralis extract by oral gavage for 90 days, as described above. The test substance was administered at concentration of 0.1 , 1.0 and $10 \%(\mathrm{w} / \mathrm{v})$ in distillate water to obtain doses of 10 , 100 and $1000 \mathrm{mg} / \mathrm{kg} /$ day. Volume doses of $\mathrm{J}$. pectoralis extract were adjusted every 7 day to achieve the targeted dose level. Animals were monitored weekly for body weight and food consumption, and daily for behavioral and clinical signs. At the completion of the subchronic study, blood samples were collected from aorta vein under anesthesia of $40 \mathrm{mg} / \mathrm{kg}$ of sodium pentobarbital and serum obtained for hematological and biochemical analyses.

After the treatment period, a satellite group of 10 animals per sex (5 control and 5 treated) was used in the top dose group for observation of reversibility or persistence of any toxic effect. In these groups, blood sample and organs were taken 28 days after 90 days treatment period.

\section{Hematology Analysis}

Hematology included determination of hematocrit by microhematocrit capillaries, hemoglobin concentration by Biologic Products Inc. (Havana, Cuba) diagnostic kit (Hemotest), erythrocyte and leukocyte count in Neubauer chamber, differential leukocyte count by extension in microscopy slides, and blood clotting time by add calcium chloride to citrated blood.

\section{Biochemical Analysis}

Clinical biochemistry included glucose, total cholesterol, urea, alanine aminotransferase (ALT), aspartate aminotransferase (AST), bilirubin, and cholinesterase. The determinations were made using diagnostic kit produced by Biologic Products Inc. (Havana, Cuba). The absorbance values were determined in a spectrophotometer Spectronic Genesys 2.

\section{Necropsy and Histopathological Examination}

After collecting blood samples, rats were euthanized by exsanguinations. All animals were subjected to a full and detailed gross necropsy. Any gross change in organs and tissues were preserved for histological examination. Selected organs for weight were liver, kidneys, adrenals, spleen and testes. Selected organs (heart, kidneys, liver, spleen, brain, lungs, stomach, intestines, thymus, adrenals, thyroid, parathyroid, trachea, pancreas, salivary glands, cervical ganglion, gonads, prostate, ovaries and seminal bladder) were removed, fixed, sectioned, and stained for histopathological examination [10].

\section{Statistics}

Data were analyzed using the one-way analysis of variance (ANOVA) and Duncan test for body weight, food consumption, blood, and organ weight data. Probability values of $p<0.05$ were considered statistically significant.

\section{RESULTS}

\section{Acute Toxicity Test}

We did not observe any signs of toxicity during the acute investigation. Mean body weight for female and male rats treated with $2000 \mathrm{mg} / \mathrm{kg}$ of $J$. pectoralis extract are

Table 1. Body Weights of Animals Treated with Single Oral Dose of J. pectoralis

\begin{tabular}{|c|c|c|}
\hline Parameter & Male & Female \\
\hline \hline Initial weight (g) & $156.7 \pm 4.9$ & $172.3 \pm 15.0$ \\
\hline Final weight (g) & $262.3 \pm 12.7$ & $234.0 \pm 21.6$ \\
\hline Weight gain (g) & $105.7 \pm 7.8$ & $61.7 \pm 31.9$ \\
\hline
\end{tabular}

Note: Values represent the mean \pm standard deviation $(n=3)$. 
Table 2. Body Weights and Food Intake of Animals Following 90-Days Exposure to J. pectoralis Extract

\begin{tabular}{|c|c|c|c|c|}
\hline Parameter (Male) & Control & $10 \mathrm{mg} / \mathrm{kg} / \mathrm{day}$ & $100 \mathrm{mg} / \mathrm{kg} / \mathrm{day}$ & $1000 \mathrm{mg} / \mathrm{kg} / \mathrm{day}$ \\
\hline Initial weight (g) & $103.7 \pm 11.5$ & $109.6 \pm 5.4$ & $105.8 \pm 11.4$ & $104.3 \pm 8.7$ \\
\hline Weight gain (g) & $247.8 \pm 46.4$ & $239.0 \pm 63.2$ & $236.7 \pm 36.8$ & $239.6 \pm 43.4$ \\
\hline Food intake (g/animal/day) & $20.2 \pm 2.8$ & $20.2 \pm 2.1$ & $20.2 \pm 2.3$ & $20.3 \pm 2.8$ \\
\hline Initial weight (g) & $99.3 \pm 9.6$ & $98.8 \pm 10.6$ & $96.8 \pm 11.0$ & $95.5 \pm 8.1$ \\
\hline Final weight (g) & $261.2 \pm 12.2$ & $279.4 \pm 25.0$ & $269.0 \pm 22.2$ & $265.0 \pm 27.6$ \\
\hline Weight gain $(\mathrm{g})$ & $122.4 \pm 26.3$ & $140.3 \pm 18.1$ & $134.5 \pm 18.2$ & $128.3 \pm 32.8$ \\
\hline Food intake (g/animal/day) & $20.2 \pm 2.1$ & $20.2 \pm 2.4$ & $20.1 \pm 3.0$ & $21.3 \pm 2.5$ \\
\hline
\end{tabular}

Table 3. Results of Hematological Parameters Following 90-Days Exposure to J. pectoralis Extract

\begin{tabular}{|c|c|c|c|c|c|}
\hline Parameter (Male) & Control & $10 \mathrm{mg} / \mathrm{kg} / \mathrm{day}$ & $100 \mathrm{mg} / \mathrm{kg} / \mathrm{day}$ & $1000 \mathrm{mg} / \mathrm{kg} / \mathrm{day}$ & Control Range \\
\hline Blood clotting time (sec) & $116.5 \pm 2.2$ & $127.5 \pm 8.9$ & $106.1 \pm 8.4$ & $81.0 \pm 9.3 * *$ & $114-119$ \\
\hline Hematocrit (\%) & $51.9 \pm 3.1$ & $54.2 \pm 3.2$ & $50.4 \pm 3.4$ & $53.9 \pm 3.3$ & $48-60$ \\
\hline Erythrocyte count $\left(\right.$ cellx $\left.10^{3} / \mathrm{mm}^{3}\right)$ & $4944 \pm 987$ & $4654 \pm 637$ & $5014 \pm 526$ & $4889 \pm 756$ & $3661-6227$ \\
\hline \multicolumn{6}{|l|}{ (Female) } \\
\hline Blood clotting time ( $\mathrm{sec}$ ) & $97.4 \pm 8.8$ & $108.0 \pm 10.9$ & $100.9 \pm 9.9$ & $124.2 \pm 8.5 * *$ & $90-105$ \\
\hline Hemoglobin (mmol/l) & $8.3 \pm 0.4$ & $8.2 \pm 0.3$ & $8.4 \pm 1.2$ & $8.7 \pm 1.2$ & $7.8-8.8$ \\
\hline Hematocrit $(\%)$ & $48.1 \pm 3.1$ & $50.8 \pm 6.9$ & $49.7 \pm 7.6$ & $45.9 \pm 3.4$ & $43-52$ \\
\hline
\end{tabular}

Note: Values represent the mean \pm standard deviation $(\mathrm{n}=10)$. Significantly different from controls $(* \mathrm{p}<0.05, * * \mathrm{p}<0.01)$.

illustrated in Table 1. Normal weight gain was observed in animals of both sexes. Abnormalities in organs and tissues were not observed in necropsy after 14 days of acute dosing.

\section{Subchronic Toxicity Test}

One female animal died in the $1000 \mathrm{mg} / \mathrm{kg} /$ day group due to accidental instillation of the test solution into the subject's trachea. There were no sings of toxicity and mortality during 90 days experimental period in treated groups. Treatment did not influence mean body weight, weight gain, and food intake of all experimental groups (Table 2).

Of the hematological parameters, blood-clotting time was affected by subchronic dosing with $J$. pectoralis (Table 3 ). Blood clotting time was significantly decreased at the highest dose in male while it was significantly increased in female. In addition, total leukocyte count was significantly increased in male treated groups and erythrocyte count was significantly reduced in female medium dose.

Of the results in differential leukocyte count assessed, lymphocyte was significantly decreased at the highest dose in male, while an increase in neutrophils was not statistically significant. In female groups, there was no difference in differential leukocyte count (Figs. 1-2).

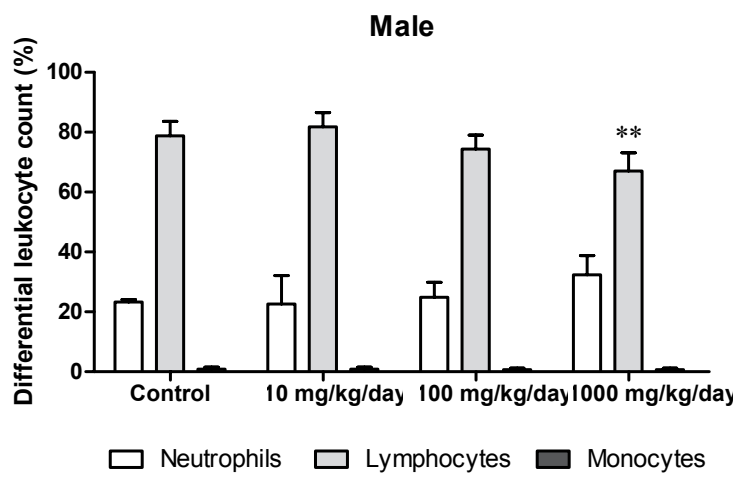

Fig. (1). Differential leukocytes counts in male Wistar rats exposed to subchronic oral doses of J. pectoralis extract. Values are mean \pm standard deviation; $\mathrm{n}=10$ animal/group; $* * p<0.01$ (significantly different from control). 


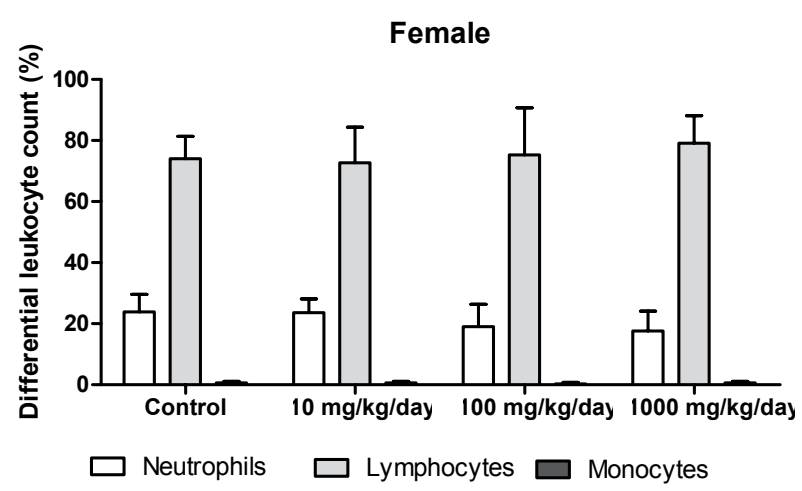

Fig. (2). Differential leukocytes counts in female Wistar rats exposed to subchronic oral doses of J. pectoralis extract. Values are mean \pm standard deviation, $\mathrm{n}=10$ animal/group.

Of the biochemical parameters, tested ALT, urea, bilirubin, and cholesterol exhibited variations in female by subchronic dosing with $J$. pectoralis. ALT and bilirubin levels were significantly decreased only at the medium and high doses. In addition, urea and total cholesterol were increased significantly at the low and medium doses (Table 4). There was no difference in the others hematological and biochemical parameters relative to control levels.

\section{Organs Weight}

There was no difference in the relative organ weight (as $\%$ of total body weight) between control and treated groups (Table 5).

Table 4. Results of Biochemical Parameters Following 90-Days Exposure to J. pectoralis Extract

\begin{tabular}{|c|c|c|c|c|c|}
\hline$A L T(U / l)$ & $42.8 \pm 7.4$ & $34.2 \pm 9.6$ & $32.4 \pm 11.4$ & $43.8 \pm 9.9$ & $38-61$ \\
\hline Urea $(\mathrm{mmol} / \mathrm{l})$ & $18.2 \pm 1.8$ & $21.0 \pm 6.4$ & $22.2 \pm 5.2$ & $23.1 \pm 5.5$ & $8.8-15.6$ \\
\hline Glucose (mmol/l) & $3.3 \pm 1.4$ & $3.1 \pm 1.5$ & $3.1 \pm 0.8$ & $2.4 \pm 0.8$ & $5.0-7.4$ \\
\hline Cholesterol (mmol/l) & $3.7 \pm 0.5$ & $4.9 \pm 0.4$ & $4.1 \pm 0.9$ & $2.7 \pm 0.8$ & $2.2-2.8$ \\
\hline Cholinesterase ( $\mu$ kat/l) & $14.4 \pm 2.8$ & $20.4 \pm 4.6$ & $15.0 \pm 4.1$ & $18.4 \pm 6.0$ & $11-18$ \\
\hline \multicolumn{6}{|l|}{ (Female) } \\
\hline Urea $(\mathrm{mmol} / \mathrm{l})$ & $19.1 \pm 5.2$ & $26.6 \pm 2.9 * *$ & $23.3 \pm 5.1$ & $21.2 \pm 5.8$ & $9.5-18.4$ \\
\hline Glucose ( $\mathrm{mmol} / \mathrm{l})$ & $3.0 \pm 1.4$ & $2.6 \pm 1.5$ & $3.5 \pm 1.4$ & $3.0 \pm 1.0$ & $5.7-6.8$ \\
\hline Bilirubin $(\mu \mathrm{mol} / \mathrm{l})$ & $20.6 \pm 7.3$ & $21.8 \pm 5.4$ & $21.9 \pm 8.2$ & $7.1 \pm 4.2^{*}$ & $9-32$ \\
\hline Cholesterol (mmol/l) & $2.1 \pm 0.6$ & $5.0 \pm 0.5^{* *}$ & $4.7 \pm 0.9 * *$ & $2.9 \pm 0.8$ & $1.7-2.8$ \\
\hline Cholinesterase $(\mu \mathrm{kat} / \mathrm{l})$ & $17.0 \pm 5.7$ & $23.3 \pm 3.3$ & $18.7 \pm 7.3$ & $19.1 \pm 4.9$ & $12-22$ \\
\hline
\end{tabular}

Note: Values represent the mean \pm standard deviation $(\mathrm{n}=10)$.** Significantly different from controls $(\mathrm{p}<0.01)$.

\section{Histology}

Histopathological examination of organs and tissues did not reveal chemically induced changes. Histopathological lesions were identified in lung, liver, and kidney. Pneumonia was observed in 5 of 10 control both sexes, 9 of 10 highdose males, and 7 of 10 high-dose females. Liver inflammation was present in one of the 10 high-dose males. Hydronephrosis was present in one of the 10 control females. Sections of the other organs were normal.

Table 6 show results obtained for hematological and biochemical parameters after 28-days recovery period. No significant effect was observed in hematological and biochemical parameters after 28-days recovery period.

\section{DISCUSSION AND CONCLUSION}

There was no indication of treatment-related effect in Wistar rats exposed to single po dose of $J$. pectoralis extract. The effects of $J$. pectoralis extract exposure in subchronic regimen varied by sex but generally affected blood clotting time and some biochemical parameters.

Variations in blood clotting time were observed in different ways in male and female rats. It was increased in female while decreased in male treated groups. These effects were within or close to normal ranges for this species and were reversible. Increase in blood clotting time observed in female rats could be due to coumarin content of the $J$. pectoralis extract, but the decrease observed in male animals was unexpected.

Coumarins are one of the constituents of the J. pectoralis extract. Coumarins are a basic structure of numerous nat- 
Table 5. Organ Weights (\% Total Body Weight) of Both Sexes of Rats Following Subchronic Oral Exposure to J. pectoralis Extract

\begin{tabular}{|c|c|c|c|c|}
\hline Parameter (Male) & Control & $10 \mathrm{mg} / \mathrm{kg} / \mathrm{day}$ & $100 \mathrm{mg} / \mathrm{kg} / \mathrm{day}$ & $1000 \mathrm{mg} / \mathrm{kg} / \mathrm{day}$ \\
\hline Adrenals & $0.012 \pm 0.003$ & $0.012 \pm 0.007$ & $0.011 \pm 0.002$ & $0.012 \pm 0.002$ \\
\hline Testis & $0.693 \pm 0.107$ & $0.769 \pm 0.118$ & $0.795 \pm 0.109$ & $0.774 \pm 0.108$ \\
\hline \multicolumn{5}{|l|}{ (Female) } \\
\hline Liver & $3.972 \pm 0.300$ & $3.447 \pm 0.467$ & $3.665 \pm 0.238$ & $3.940 \pm 0.844$ \\
\hline Kidney & $0.673 \pm 0.045$ & $0.592 \pm 0.075$ & $0.553 \pm 0.060$ & $0.575 \pm 0.142$ \\
\hline Adrenals & $0.028 \pm 0.004$ & $0.027 \pm 0.006$ & $0.029 \pm 0.005$ & $0.031 \pm 0.006$ \\
\hline
\end{tabular}

Table 6. Results of Hematological and Biochemical Parameters Following 28-Days Recovery Period

\begin{tabular}{|c|c|c|c|c|}
\hline Parameter & \multicolumn{2}{|c|}{ Male } & \multicolumn{2}{|c|}{ Female } \\
\hline Erythrocyte count $\left(\right.$ cell $\left.x 10^{3} / \mathrm{mm}^{3}\right)$ & $5458 \pm 168$ & $5678 \pm 564$ & $5219 \pm 802$ & $4847 \pm 861$ \\
\hline Leukocyte count $\left(\mathrm{cell} / \mathrm{mm}^{3}\right)$ & $6560 \pm 1749$ & $6770 \pm 601$ & $6788 \pm 1644$ & $6705 \pm 758$ \\
\hline Cholesterol (mmol/l) & $2.1 \pm 0.8$ & $1.9 \pm 0.6$ & $1.7 \pm 0.3$ & $1.8 \pm 0.5$ \\
\hline Urea (mmol/l) & $16.1 \pm 5.1$ & $15.6 \pm 2.2$ & $14.0 \pm 0.4$ & $15.6 \pm 2.2$ \\
\hline Bilirubin $(\mu \mathrm{mol} / \mathrm{l})$ & $45.3 \pm 16.3$ & $40.6 \pm 21.3$ & $20.8 \pm 8.9$ & $21.6 \pm 5.5$ \\
\hline
\end{tabular}

Note: Values represent the mean \pm standard deviation $(n=5)$.

urally occurring compounds with important and diverse physiological activities and inhibit the production of the vitamin K-dependent coagulation factor by the liver [11]. In a previous study, platelet counts were significantly decreased in male and female rats that receive 3,4-dihydrocoumrin [12].

Coumarin is a well-recognized rat hepatotoxicant in men and animals [13-15]. Coumarin can cause toxic effect through 3,4-epoxide intermediate, which may be responsible for its toxic effects. The occurrence of liver injuries is rather rare and happens predominantly when doses are significantly higher than necessary for therapeutical use. These adverse effects caused by coumarin can be detected only in very high concentrations considerably above the regular therapeutical dosage [16]. J. pectoralis extract has approximately $1 \%$ of coumarin. With a dose of $1000 \mathrm{mg} / \mathrm{kg} /$ day of $J$. pectoralis extract, $10 \mathrm{mg}$ of coumarin was delivered. The exposure dose of coumarin, in our study, was low and there was no indication of hepatotoxic effect in our investigation.

On the other hand, some coumarins have beneficial effect causes reduction of plasma ALT and inhibit caspase-3 activation [17]. Slight decrease of ALT levels observed in female medium dose could be due to coumarins contents of the extract. The effect was week, not dose-related, and very close to normal range. For that, it is considered that the slight decrease of ALT activity could be due to no-treatment related experimental variations.

Leukocytosis is an increase in the number of leukocytes above the normal level. Neutrophils are the first line of cellular defense that respond to infectious agent, tissue injury, and inflammatory process. Disease processes as pneumonia could be responsible for leukocytosis observed in male treated animals. More incidence of pneumonia was observed in male than female. Neutrophils were slightly increased and lymphocytes were significantly decreased in males as a respond to this process. Pneumonia is a histopathological lesion frequent in younger animals on gavage experiments. This lesion was not presented after 28-days of recovery period as well as leukocytosis. The other tissue lesions observed are frequently found in rats that can affect up to $6 \%$ (liver inflammation) and $10 \%$ (hydronephrosis) of control rats. Therefore, histopathological lesions observed were not related to the treatment. 
Variations of urea and cholesterol levels were over to normal ranges and were reversible. Hypercholesterolemia has been reported in renal disease, liver disease, hypothyroidism and diabetes mellitus [18]. Nevertheless, any histopathological signs in liver, kidney, thyroids and pancrease were observed in animals of treated groups. Glucose levels and hepatic enzymes were not increased in the treated animals. The reasons for urea and cholesterol levels increase in female treated rats could be due to slight influence of the metabolites of the extract on renal function. These variations were slight, reversible and did not change the integrity of organs and tissues. The decrease observed in bilirubin levels in males could be due to no-treatment related experimental variations because liver or kidney lesions related to the treatment were not observed.

In this study, the effects observed are low and include slight variations in blood clotting time and some biochemical parameters. In summary, $2000 \mathrm{mg} / \mathrm{kg}$ orally was the acute NOAEL for $J$. pectoralis extract, for the absence of toxic respond. One thousand $\mathrm{mg} / \mathrm{kg}$ orally was found to be the subchronic NOAEL for $J$. pectoralis extract, for effects other than transient variations in blood clotting time and biochemical parameters, under the conditions of this investigation.

\section{REFERENCES}

[1] Lino, C.S.; Traveira, M.L.; Viana, G.S.B.; Matos, J.J. Analgesic and antiinflammatory activities of Justicia pectoralis Jacq and its main constituents: coumarin and umbelliferone. Phytother. Res., 1997, 11, 211-215.

[2] Leal, L.K.; Ferreira, A.A.; Bezerra, G.A.; Matos, F.J.; Viana, G.S. Antinociceptive, anti-inflammatory and bronchodilator activities of Brazilian medicinal plants containing coumarin: a comparative study. J. Ethnopharmacol., 2000, 70(2), 151-159.

[3] Fernández, L.; Menéndez, R.; Fernández, J.; Más, R.M. Justicia pectoralis: efectos sobre una tarea de evitación pasiva de una sola prueba en ratones. Rev. CNIC, Cienc. Biol., 1991, 22, 1-2.

[4] Rodríguez, E.C.; Virvés, A.T.; Alemán, S.C.L. Estudio preliminar del efecto de la Justicia pectoralis sobre el EEG de adultos normales. Rev. Cubana Farm., 1989, 23, 302-308.
[5] Silva, R.L.; Acosta, L.L.; Castro, I.E. In Fundamentos de Agrotecnología de Cultivos de Plantas Medicinales Iberoamericanas; Martínez, J.V.; Bernal, H.Y.; Cáceres, A. Ed.; QuebecorImpreandes: Santafé de Bogotá, 2000; pp. 217-28.

[6] Remigio, A.C.; Pérez, G.; Fernández, N.; Bada, A.M.; Arteaga, M.E.; Mancebo, A. Estudio genotóxico in vivo de 6 extractos de plantas medicinales en células de la médula ósea de roedores. Rev. Toxicol., 2001, 18, 75-8.

[7] USP 30. United State Pharmacopeia 30 - NF 25. US Pharmacopeial Convention Inc. 921. Water determination, 2007.

[8] Rodríguez, J.E.; López, O.D.; Gil, J.M. Método para la cuantificación de cumarina en extracto seco a partir de extractos de Justicia pectoralis Jacq. Rev. Cubana Plant Med., 2008, 13(3), ISSN 10284796 on-line version.

[9] OECD. Guideline for Testing of Chemical. "Acute Oral Toxicity Acute Toxic Class Method" No 423, 2001.

[10] OECD. Guideline for Testing of Chemicals. Subchronic Oral Toxicity - Rodent: 90 day study. No 408, 1998.

[11] Visser, L.E.; Bleumink, G.S.; Trienekens, P.H.; Vulto, A.G.; Hofman, A.; Stricker, B.H. The risk of overanticoagulation in patients with heart failure on coumarin anticoagulants. $B r . J$. Haematol., 2004, 127(1), 85- 9.

[12] National Toxicology Program. N.T.P. Toxicology and carcinogenesis studies of 3,4-dihydrocoumarin (CAS No 119-84-6) in F344/N rats and B6C3F1 mice (gavage studies). Natl. Toxicol. Program Tech. Rep. Ser., 1993, 423, 1-336.

[13] Born, S.L.; Api, A.M.; Ford, R.A.; Lefever, F.R.; Hawkins, D.R. Comparative metabolism and kinetics of coumarin in mice and rats. Food Chem. Toxicol., 2003, 41(2), 247-58.

[14] Kremer Hovinga, J.A.; Wuillemin, W.A. Recurrent hepatitis in oral anticoagulation: coumarin-induced hepatitis. Ther. Umsch., 1999, 56(9), 513-5.

[15] Andrejak, M.; Gersberg, M.; Sgro, C.; Decocq, G.; Hamel, J.D.; Morin, M.; Gras, V. French pharmacovigilance survey evaluating the hepatic toxicity of coumarin. Pharmacoepidemiol. Drug Saf., 1998, 7(Suppl 1), S45- 50.

[16] Adam, B.S.; Pentz, R.; Siegers, C.P.; Strubelt, O.; Tegtmeier, M. Troxerutin protects the isolated perfused rat liver from a possible lipid peroxidation by coumarin. Phytomedicine, 2005, 12(1-2), 5261.

[17] Okamoto, T.; Kobayashi, T.; Yoshida, S. Chemical aspects of coumarin compounds for the prevention of hepatocellular carcinomas. Curr. Med. Chem. Anticancer Agents, 2005, 5(1), 47-51.

[18] Suber, R.L. In Principles and Methods of Toxicology; W. Hayes, Ed.; Raven Press: New York, 1989, pp. 485-519.

Received: January 27, 2009

Revised: February 11, 2009

Accepted: March 11, 2009

(C) Lagarto et al.; Licensee Bentham Open.

This is an open access article licensed under the terms of the Creative Commons Attribution Non-Commercial License (http://creativecommons.org/licenses/by-nc/3.0/) which permits unrestricted, non-commercial use, distribution and reproduction in any medium, provided the work is properly cited. 